\title{
Substitution of Antibodies and Receptors with Molecularly Imprinted Polymers in Enzyme-Linked and Fluorescent Assays
}

\section{Sergey A. Piletsky*, Elena V. Piletska, Alessandra Bossi, Khalku Karim, Philip Lowe and Anthony P. F. Turner}

Institute of BioScience and Technology, Cranfield University, Silsoe, Bedfordshire, MK45 4DT, UK; E-mail: S.Piletsky@cranfield.ac.uk.

\begin{abstract}
A new technique for coating microtitre plates with molecularly imprinted polymers (MIP), specific for low-molecular weight analytes (epinephrine, atrazine) and proteins is presented. Oxidative polymerization was performed in the presence of template; monomers: 3-aminophenylboronic acid, 3-thiopheneboronic acid and aniline were polymerized in water and the polymers were grafted onto the polystyrene surface of the microplates. It was found that this process results in the creation of synthetic materials with antibody-like binding properties. It was shown that the MIP-coated microplates are particularly useful for assay development. The high stability of the polymers and good reproducibility of the measurements make MIP coating an attractive alternative to conventional antibodies or receptors used in ELISA.
\end{abstract}

Keywords: fluorescent immunoassay, ELISA, conjugated polymers, grafting on microplates, molecular imprinting

*To whom correspondence should be addressed. 


\section{INTRODUCTION}

Enzyme-linked immunoassay (ELISA) is probably the most common used method in clinical, environmental, agricultural/food and forensic laboratories for the analysis of proteins, hormones, micro-organisms, DNA sequences and drugs (Basta et al., 1989; Stanley, S et al., 1991; Bachand et al., 1998; Thacker et al., 1998; Mahoney et al., 1999). Immunoassays are rapid, sensitive and selective for the analyte of interest and are generally cost effective for large sample loads. However, as with any technology there are disadvantages, for example, the reagent stability and the high expense of producing antibodies are often cited as problems. In addition, the production of antibodies for toxins and immunodepressants is particularly difficult due to their adverse action on the metabolism and the immune system.

In this regard molecularly imprinted polymers have already been identified as stable artificial mimics, suitable for the substitution of receptors and antibodies in assays or sensors (Vlatakis et al., 1993; Piletsky et al., 1998; Mirsky et al., 1999, Surugiu et al., 1999). Their most significant advantages are inherent stability, low cost and ease of preparation (Kriz et al., 1994; Wulff, 1995). However, MIPs have shortcomings, such as lack of true water compatibility as well as difficult immobilization procedures. In particular, the absence of a reproducible method of coating microplate wells with MIPs impairs their application in assays where this format is preferable. Here we present a new method of microplate modification with imprinted polymers based on aniline and thiophene derivatives. Low-molecular weight organic substances, such as epinephrine and atrazine, and proteins with different molecular weight such as microperoxidase, horseradish peroxidase (HRP) and lactoperoxidase were selected as templates for these experiments. The fundamental significance of this 
approach lies in the development of a new method for synthesis of artificial receptors using molecular imprinting in conjugated polymers. Besides the theoretical interest, this work has practical significance for the development of assays for environmental monitoring and the pharmaceutical industry (drug discovery).

\section{EXPERIMENTAL SECTION}

\section{Materials}

Ammonium persulfate, cytochrome $\mathrm{C}$ from horse heart muscle and glutaric dialdehyde were purchased from Aldrich (Dorset, UK). Microperoxidase was purchased from Biozyme laboratories (Blaenavon, UK). Lactoperoxidase from bovine milk was from Fluka (Buchs, Switzerland). 2,2'-Azino-bis(3-ethylbenzthiazoline-6-sulfonic acid (ABTS), horseradish peroxidase from horseradish roots, Tween-20 and acetic acid were purchased from Sigma (Dorset, UK). Polystyrene microplates were from Corning, (Corning, NY). All other chemicals and solvents (HPLC grade) were obtained from commercial sources and used as received.

Grafting of the polymers to the microplate surface. Monomers were polymerized on the microplate walls using the following procedure: $50 \mu$ l solution of aniline hydrochloride $(720 \mathrm{mM})$ in water was placed in microplate wells using a multichannel pipette and mixed at $22{ }^{0} \mathrm{C}$ with a $50 \mu \mathrm{l}$ solution of $\left(\mathrm{NH}_{4}\right)_{2} \mathrm{~S}_{2} \mathrm{O}_{8}(250 \mathrm{mM})$. 3Aminophenylboronic acid was polymerized by mixing together a $50 \mu \mathrm{l}$ solution of 3aminophenyl boronic acid $(100 \mathrm{mM})$ with a $50 \mu \mathrm{l}$ solution of $\left(\mathrm{NH}_{4}\right)_{2} \mathrm{~S}_{2} \mathrm{O}_{8}(50 \mathrm{mM})$. 3Thiopheneboronic acid was polymerized by using $50 \mu \mathrm{l} \mathrm{K} \mathrm{Cr}_{2} \mathrm{O}_{7}(200 \mathrm{mM})$ instead of ammonium persulfate as oxidizer. Polymerization of the imprinted polymers was performed in anoxygen atmosphere in the presence of template $(1 \mathrm{mg} / \mathrm{ml}$ concentration). 
The reaction was carried out with gentle stirring for 20-60 min. After polymerization the microplates were washed 3 times with deionized water, 5 times with $10 \mathrm{mM} \mathrm{HCl}$ and then with water again. The efficiency of the washing procedure for imprinted enzymes was evaluated by measuring the residual enzymatic activity. ABTS (6 mg) solution was dissolved in $10 \mathrm{ml}$ Na-citrate buffer (0.1 M, pH 6.0) and mixed with $3 \mu \mathrm{l}$ of 30 wt. \% $\mathrm{H}_{2} \mathrm{O}_{2}$. An aliquot of $100 \mu \mathrm{l}$ of the solution was added to a microplate well containing sample of the membrane and incubated for $10 \mathrm{~min}$ at room temperature. The optical density of the solution was measured at $450 \mathrm{~nm}$ using a MR700 Microplate Reader (Dinex Technologies Inc., Edgewood, NY). The measurements indicated that 7-10\% of the enzyme remained trapped in the polymer.

Conjugate preparation. Horseradish peroxidase (4 mg) (EC1.11.1.7 from horseradish roots, MW 44000 Da, Sigma) was dissolved in $1 \mathrm{ml}$ norepinephrine or desethylatrazine solution in water $(1 \mathrm{mM})$. An aliquot $(5 \mu \mathrm{l})$ of glutaric dialdehyde solution in water (10 wt. \%) was added to the mixture and incubated for 1 hour at room temperature. The reaction was stopped by addition of $200 \mu \mathrm{l}$ lysine solution (50 mg/ml). The solution was filtered through a macrofilter (Ultra-Spin Macrofilter, Roth, Germany) to separate molecules with molecular weight $>10 \mathrm{kDa}$, and washed with buffer. The activity of the conjugated enzyme was found to be 400-450 units per mg solid (determined using $\mathrm{H}_{2} \mathrm{O}_{2}$ /ABTS).

Enzyme-linked assay. Binding of the $\beta$-receptor agonists to the microplates coated with either MIP or blank polymers, was measured using a competitive reaction between HRP-N conjugate (HRP-A in the case of atrazine assay) and free analyte. A $50 \mu \mathrm{l}$ aliquot of corresponding analytes (0-1 mM concentrations) and $50 \mu \mathrm{l}$ HRP-N or HRP-A conjugate $(625 \mathrm{ng} / \mathrm{ml})$ were mixed in the microplate wells and incubated for 1 hour at 
room temperature. The microplates were then washed three times with 0.005 wt. \% Tween-20 and Na-phosphate buffer (25 mM pH 7.5). The reaction of HRP with hydrogen peroxide and ABTS was used to measure the conjugate adsorbed on the polymer. Six milligrams of ABTS solution was dissolved in $10 \mathrm{ml}$ Na-citrate buffer (0.1 M, pH 6.0) and mixed with $3 \mu \mathrm{l} 30$ wt. $\% \mathrm{H}_{2} \mathrm{O}_{2}$. An aliquot (100 $\left.\mu \mathrm{l}\right)$ of this solution was added to each well and incubated for $35 \mathrm{~min}$ at $22{ }^{0} \mathrm{C}$. Optical absorbance was measured at $450 \mathrm{~nm}$ using a microplate reader. The dissociation constants were determined using the Scatchard analysis. The apparent $K_{D}$ values were calculated from the equation $K_{D}=$ $\mathrm{EC}_{50} /(1+$ [conjugate $] / \mathrm{K}_{\mathrm{D}}$ conjugate $)$. The $\mathrm{K}_{\mathrm{D}}$ conjugate value was determined by measuring the sorption by the polymer of horseradish peroxidase conjugate with norepinephrine, using seven concentrations of conjugate ranging from 10 to $750 \mathrm{ng} / \mathrm{ml}$ $\left(\mathrm{K}_{\mathrm{D}}\right.$ conjugate $\left.=41.4 \mathrm{nM}\right)$. All measurements were made in triplicate.

Fluorescent assay. Atrazine binding was measured using a competitive reaction between fluorescent triazine derivative 5-(4,6-dichlorotriazinyl)aminofluorescein (FT) conjugate (Molecular Probes, Leiden, The Netherlands) and free analyte. A $50 \mu \mathrm{l}$ aliquot of corresponding analytes (0-1 mM concentrations) and $50 \mu \mathrm{l}$ FT conjugate (5 $\mathrm{ng} / \mathrm{ml}$ ) were mixed in the microplate wells and incubated for 1 hour at room temperature. After incubation for 4 hours at room temperature, the fluorescence of analyte was measured using a fluorimeter, Fluoro Max-2 (Instruments SA, UK), at a wavelength of $512 \mathrm{~nm}$ (excitation= $490 \mathrm{~nm}$ ) in order to estimate the quantity of displaced conjugate.

Analysis of the enzyme binding to the polymer. Protein solutions with concentrations of $100,30,10,3,1,0.3$ and $0.1 \mu \mathrm{g} / \mathrm{ml}$ were prepared in $50 \mathrm{mM}$ sodium-phosphate buffer, pH 7.0 containing $0.1 \%$ Tween-20 and added in $100 \mu$ laliquots to the microplate 
wells. After 90 min incubation, the plates were washed with the same buffer to remove the non-adsorbed protein and the quantity of bound protein was measured by determination of its peroxidase activity using ABTS as substrate. ABTS solution (6 mg) was dissolved in $10 \mathrm{ml}$ Na-citrate buffer $(0.1 \mathrm{M}, \mathrm{pH}$ 6.0) and mixed with $3 \mu \mathrm{l}$ of $30 \mathrm{wt}$. $\% \mathrm{H}_{2} \mathrm{O}_{2}$. Solution $(100 \mu \mathrm{l})$ was added to microplate well containing membrane sample and incubated for $10 \mathrm{~min}$ at room temperature. The optical density of the solution was then measured at $450 \mathrm{~nm}$ using a MR700 Microplate Reader (Dinex Technologies Inc., Edgewood, NY). All the measurements were made in triplicate. The data obtained were plotted in a Scatchard plot and dissociation constants were calculated.

Polymer visualization. The bottom of the microplate wells coated with the polymer samples were cut from the microplate and fixed on a silicon support. Atomic Force Microscope (AFM) images were obtained using the Quesant Resolver model (Quesant Instrument Corporation, Hills, CA). Samples were scanned in wave-mode, at a scan rate of $2 \mathrm{~Hz}$ and 400 pixel resolution.

\section{RESULTS AND DISCUSSION}

The possibility of coating microplates with MIP was demonstrated for different templates: epinephrine, atrazine, and proteins. Two of them are small organic molecules and the others are relatively large molecules with molecular weight ranging from 1.1 $\mathrm{kDa}$ (microperoxidase) to $77 \mathrm{kDa}$ (lactoperoxidase). We chose these substances as template because they provide a convenient example to demonstrate the possibilities of the method and its performance. Not only did the size of molecule vary in our experiments, but also the type of monomer-template interaction. 
Formation of a stable complex between functional monomers and the template is crucial for the development of specific molecularly imprinted polymers. Epinephrine has several functional groups, which are binding points for the interaction with the functional monomer: a diol group in the aromatic ring, hydroxyl group and a secondary amino group (Figure 1). This structure predetermined the choice of the functional monomer, which in our case was 3-aminophenylboronic acid (APBA). Depending on solvent polarity and $\mathrm{pH}$, poly-3-aminophenylboronic acid is able to form reversible covalent bonds between boronic acid and catechol, and electrostatic interactions between boronic acid and the secondary amino and hydroxyl groups in the template.

Atrazine is poorly soluble in water $\left(\approx 10^{-4} \mathrm{M}\right)$. Additionally it only has secondary amino groups able to interact with the polymer. This makes it necessary to perform the polymerization in a mixed water-organic solvent environment using functional monomers containing, preferably, acidic functionalities (Table 1).

Protein imprinting has been done before (Liao et al., 1996) using acrylamide as a functional monomer. It was postulated that specificity in the case of a large template can be more efficiently realized through weak multipoint interactions rather than exploring a few strong ones. Because of this, we chose aniline and APBA for protein imprinting.

The MIP deposition on the microplate well surface was performed by a chemical oxidation initiated by ammonium persulfate (Pringsheim et al., 1997). In the case of thiophene derivatives we used a stronger oxidant - potassium dichromate. The ability of the monomers to form a thin polymer coating on the microplate well surface was evaluated (Table 1). The best coatings (taking into account stability of the polymer films and reproducibility of the coating) were obtained with aniline, APBA and 3- 
thiopheneboronic acid (TBA). As a result, all the following experiments were performed only with these monomers.

Depending on the monomer composition, the polymerization process lasted from 20 min (aniline derivatives) to $1 \mathrm{~h}$ (thiophene derivatives). The topography of the polymer coatings was visualized using AFM (Figure 2). Both types of polymers, MIP and blank gave almost identical images indicating little physical effect of the imprinting on the surface morphology. The size of the template also had no effect on the polymer topography. Hence, only images of MIP samples are presented here. Grafted polymers produced relatively smooth and reproducible surface coatings with an average roughness of about $40-100 \mathrm{~nm}$. The roughness of polymers made from thiophene derivatives was, in general, higher than those made from polyanilines, although polyTBA and PANI images are very similar. All polymer coatings were transparent, homogeneous and suitable for optical measurements. The deviation in the optical density of the polymer between the wells of the microplate was less than $5 \%$.

The washing procedure is very important for assay development and it was analyzed in experiments where buffers with different pHs (in presence and absence of detergents) and different times of the treatment were applied. Since the oxidation polymerization partially degrades the template and thus makes a correct analysis of the residual quantity of the template in polymer impossible, the washing conditions were optimized for each template separately analyzing the affinity of polymers after each washing step (Figure 3). As was shown before (Kriz et al., 1995; Gross et al., 1997) PANI grafted to the inert surface possess sufficient porosity permitting mobility of the solvent and analyte inside of the polymer matrix. In general, $80-90 \%$ of the template was removed from the polymer (judging from the residual activity of the imprinted 
enzymes). The capacity of specific binding sites, measured under saturation conditions gave a value: $2-15 \mu \mathrm{mol} / \mathrm{m}^{2}$ of the modified surface which depends on the size of template. Actually, the presence of small residual amounts of template in the polymer was essential for successful recognition. This can be seen clearly from the presence of the minimum on the curve illustrating the influence of the washing procedure on the EC50 value (Figure 3). The nature of this phenomenon will be discussed elsewhere.

As previously reported (Piletsky, et al., 2000) microplates coating with the epinephrine-imprinted polymer can be used successfully in an enzyme-linked assay using competition between free ligand and HRP-N conjugate. The result, presented in Figure 4, clearly indicates high specificity of the imprinted polymer for epinephrine. Ligands with only slight structural differences from epinephrine had much weaker binding to the MIP than the template. The dissociation constant for epinephrine/blank polymer $\mathrm{K}_{\mathrm{D}}=150 \pm 15 \mu \mathrm{M}$ and for epinephrine/MIP $\mathrm{K}_{\mathrm{D}}=9.2 \pm 2 \mu \mathrm{M}$, which is similar to natural receptors (Mukherjee et al., 1975). The difference in epinephrine binding to the MIP and blank polymer clearly indicates the role of the imprinting process in the formation of specific binding sites.

Atrazine imprinting was performed using ethanol/water solution $(1: 1, \mathrm{v} / \mathrm{v})$, in which the template is more soluble. Several monomers based on aniline and thiophene derivatives were tested for their ability to form an atrazine-specific MIP (Table 1). The negative charge of the enzyme created a problem for the binding of horseradish peroxidase-atrazine conjugate (HRP-A) to negatively charged polymers. This resulted in very little binding of the conjugate to the polymer. To improve the assay performance, binding experiments were performed using a competition reaction between a commercially available fluorescent analogue of atrazine (FT) and free atrazine for 
binding to the polymer. In all cases only thiophene derivatives formed MIPs with noticeable affinity towards atrazine. Nitrogen containing anilines were most probably competing with atrazine for binding to acidic groups.

In our experiments, sorption of FT and atrazine to the polymer was performed for 5 hours, resulting in $70 \%$ of the maximum sorption being achieved. The detection limit for atrazine was $8 \mu \mathrm{M}$. Better results were obtained when an atrazine-imprinted composite polymer was prepared from 3-thiopheneboronic and 3-aminophenylboronic acid (TBA/APBA) (Figure 5). The resulting composite was more specific and more sensitive, giving a detection limit $0.7 \mu \mathrm{M}$. An important indication of the imprinting process is the almost complete absence of competition between atrazine and fluorescein triazine for binding to the blank polymer. Practically no influence of metribuzin, and only a slight effect of atraton-D was observed on the FT sorption (Figure 5). Probably the heteropolymer has a better ability than the homopolymer to form and maintain highly specific binding sites. The optimal ratio between concentrations of TBA and APBA was found to be $10: 1$.

The possibility to imprint polyaniline and poly-APBA with large protein molecules was studied. Due to strong positive charges, the polyaniline coating has too strong affinity for negatively charged protein molecules and it was difficult to discriminate between specific and non-specific binding. Better results were obtained when poly-APBA was used as a matrix. Poly-APBA possesses an equal number of positive and negative residues, instead of a prevalence of protonated or deprotonated groups, thus better complementary matching with the template could be envisaged. MIPs prepared with lactoperoxidase, HRP, Cytochrome C and microperoxidase were checked for their ability to re-bind templates at $\mathrm{pH} 7$, and the results are displayed in 
Table 2. From the re-binding experiments it was evident that the size (shape) of the molecule and its charge affects the imprinting efficiency. For a small protein such as microperoxidase, the dissociation constant was rather high: $\mathrm{Kd}=150 \mu \mathrm{M}$. Large proteins, such as lactoperoxidase and horseradish peroxidase, possess much lower Kd, in the range 1-4 $\mu \mathrm{M}$. Charge influence also affects significantly the formation of binding sites and the polymer affinity. Thus, highly positively charged proteins such as Cytochrome C (pI 10.6) are not able to form imprints in the APBA polymer due to its low affinity to the polymer, which has a net positive charge.

In all cases the shelf-life stability of the MIP coated microplates was very good. After two months a very small decrease in polymer affinity was observed (10-20\%). It was assumed that the structure of the specific binding sites in the MIP is preserved because of two factors: partial cross-linking of the polymers during polymerization and fixation of the polymer chains to the microplate well surface. More detailed analysis of the role of these factors in MIP specificity is currently under investigation.

Summarizing, the feasibility of developing a microplate coating with a polymer which is specific for small organic molecules, such as epinephrine and atrazine, and for large protein molecules was demonstrated. The polymer coatings are stable and reproducible. These polymers can be used successfully as antibody and receptor substitutes in assays, High Throughput Screening and drug discovery. 


\section{REFERENCES}

Bachand, G. D., Castello, J. D. (1998). Seasonal pattern of tomato mosaic tobamovirus infection and concentration in red spruce seedlings. Appl. Envir. Microbiol. 64, 1436-1441.

Basta, M., Karmali, M., Lingwood, C. (1989). Sensitive receptor-specified enzymelinked immunosorbent- assay for esherichia coli verotoxin. J. Clin. Microbiol., 27, 1617-1622.

Gross P., Gibson T., Bergel A., Comtat M. (1997). Permeability enhancement of electropolymerized thin organic films. J. Electroanal. Chem, 437, 125-134.

Kriz D., Mosbach K. (1994). Competitive amperometric morphine sensor based on an agarose immobilized molecularly imprinted polymer. Anal. Chim. Acta 300, 71-75.

Kriz, D., Andersson, L. I., Khayyami, M., Danielsson, B., Larsson, P.-O., Mosbach, K. (1995). Preparation and characterization of composite polymers exhibiting both selective molecular recognition and electrical conductivity. Biomimetics, 3, 81-90.

Liao, J. L., Wang, Y., Hjertén, S. (1996). A novel support with artificially created recognition for the selective removal of proteins and for affinity chromatography. Chromatographia 42, 259-262.

Mahoney, C. W., Hosoi, T., Ohashi, M. (1999). High-throughput nonradioisotopic detection of picomole levels of phosphothreonine and phosphoserine containing peptides via biotinylation and enzyme-linked immunosorbent assay. Anal. Biochem. 268, 371-376.

Mirsky, V. M., Hirsch, T., Piletsky, S. A., Wolfbeis, O. S. (1999). Spreader-bar approach to molecular architecture: formation of artificial chemoreceptors.Angew. Chemie, Intern. Ed. 38/8, 1108-1110. 
Mukherjee C., Caron M. G., Mullikin D., Lefkowitz R. J. (1975). Structure-activity relationships of adenylate cyclase-coupled beta adrenergic receptors: determination by direct binding studies. Mol. Pharm. 12, 16-31.

Piletsky S. A., Piletskaya E. V., Panasyuk T. L., El’skaya A. V., Levi R., Karube I., Wulff G. (1998). Imprinted membranes for sensor technology - opposite behavior of covalently and noncovalently imprinted membranes. Macromolecules 31, 21372140.

Piletsky S. A., Piletska E. V., Chen B., Karim K., Weston D., Barrett G., Lowe P., Turner A. P. F. (2000). Chemical grafting of molecularly imprinted homopolymers to the surface of microplates. Application of artificial adrenergic receptor in enzyme-linked assay for $\beta$-agonists determination. Anal. Chem., 72, 4381-4385.

Pringsheim E., Terpetschnig E., Wolfbeis O. S. (1997). Optical sensing of $\mathrm{pH}$ using thin films of substituted polyanilines. Anal. Chim. Acta, 357, 247-252.

Stanley, S., Jeganathan, A., Wood, T., Henry, P., Turner, S., Woods, W. E., Green, M., Tai, H. H., Watt, D., Blake, J., Tobin, T. (1991). Morphine and etorphine. 14. Detection by ELISA in equine urine. J. Anal. Toxicol. 15, 305-310.

Surugiu I., Ye L., Yilmaz E., Dzgoev A., Danielsson B., Mosbach K, Haupt K. (1999). An enzyme-linked molecularly imprinted sorbent assay. Analyst, 125, 13-16.

Thacker, J. D., Casale, E. S. (1998). A high-throughput ELISA system for surface water and groundwater analysis. Anal. Chim. Acta. 376, 61-65.

Vlatakis G., Andersson L. I., Müller R., Mosbach K. (1993). Drug assay using antibody mimics made by molecular imprinting. Nature 361, 645-647. 
Wulff, G. (1995). Molecular imprinting in cross-linked materials with the aid of molecular templates - a way towards artificial antibodies. Angew. Chem. Int. Ed. Engl. 34, 1812-1832.

Acknowledgment. S.P. acknowledges with gratitude a fellowship from the Leverhulme Trust. 


\section{FIGURE CAPTIONS}

Figure 1. Structure of the monomers, templates and polymers formed in the process of microplate coating with imprinted polymers.

Figure 2. The surface topography of the microplates coated with imprinted polymers: epinephrine-imprinted poly-APBA (a); atrazine-imprinted poly-TBA (b) and HRPimprinted PANI (c).

Figure 3. Influence of the washing procedure on the properties of a MIP specific for epinephrine. Absorbance of the polymer film was measured at $450 \mathrm{~nm}$. EC50 is the concentration of analyte, which produces $50 \%$ of the maximal response.

Figure 4. Structure of the analytes used in assay and their affinity to epinephrineimprinted MIP.

Figure 5. Influence of herbicide on FT sorption to imprinted poly-TBA-APBA (10:1) in water. I - fluorescence of the FT solution, taken from the wells after equilibration with herbicide. Io- fluorescence of the FT solution, taken from the wells where no herbicide is added. 
Table 1.Ability of the monomers to form a stable coating.

\begin{tabular}{|l|l|l|}
\hline Monomer & Grafting ability & Stability of the coating \\
\hline Aniline derivatives: & & \\
\hline Aniline & + (at pH 2-4) & Excellent \\
\hline Aniline-2-sulfonic acid & - & \\
\hline 3-Aminophenylboronic acid & + (at pH 2-8) & Good \\
\hline p-Aminophenylacetic acid & - & \\
\hline p-Aminobenzoic acid & + (at pH 2-5) & Poor \\
\hline Anthranilic acid & - & \\
\hline 3-Aminobenzoic acid & + (at pH 2-5) & Poor \\
\hline Thiophene derivatives: & & Good \\
\hline 3-Thiophenecarboxylic acid & + (in the absence of salt) & Good \\
\hline 3-Thiophenemalonic acid & - & \\
\hline 3-Thiopheneacetic acid & + (in the absence of salt) & Good \\
\hline 3-Thiopheneboronic acid & + (in the absence of salt) & Good \\
\hline -Afting abilty was assessed by ormation of a visible & & \\
\hline
\end{tabular}

Grafting ability was assessed by formation of a visible layer of polymer film on the microplate well surface as a result of polymerization. Stability of the coating was evaluated in washing experiments with excess of water, containing 0.05\% Tween-20. “Excellent” indicates that practically no change in optical density was observed after polymer washing; "good" - corresponds to $10 \%$ loss in absorbance; and "poor" means that more than $20 \%$ of the polymer were washed out during its treatment. 
Table 2. Binding of the proteins to polymers grafted to the microplate surface. Binding was performed in $50 \mathrm{mM}$ sodium-phosphate buffer, $\mathrm{pH}$ 7.0.

\begin{tabular}{|c|c|c|c|c|}
\hline $\begin{array}{c}\text { Polymer/K } \\
\mu \mathrm{M}\end{array}$ & $\begin{array}{c}\text { Micro- } \\
\text { peroxidase }\end{array}$ & Cytochrome C & Horseradish & Lactoperoxidase \\
peroxidase & \\
\hline MIP & $15 \pm 11$ & $>1000$ & $1.6 \pm 0.05$ & $0.36 \pm 0.1$ \\
\hline Blank & $109 \pm 11$ & $>1000$ & $4.7 \pm 0.7$ & $1.0 \pm 0.1$ \\
\hline
\end{tabular}




\section{Templates}

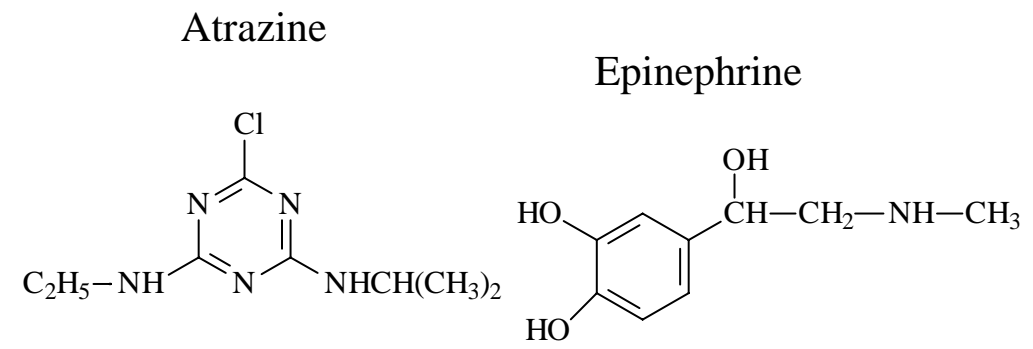

Proteins

\section{Monomers}

3-Thiopheneboronic acid

3-Aminophenylboronic acid

Aniline

$(\mathrm{OH})_{2} \mathrm{~B}$<smiles>Fc1ccsc1</smiles><smiles>Nc1cccc(OCO)c1</smiles><smiles>Nc1ccccc1</smiles>

\section{Polymers}

poly-TBA

PANI
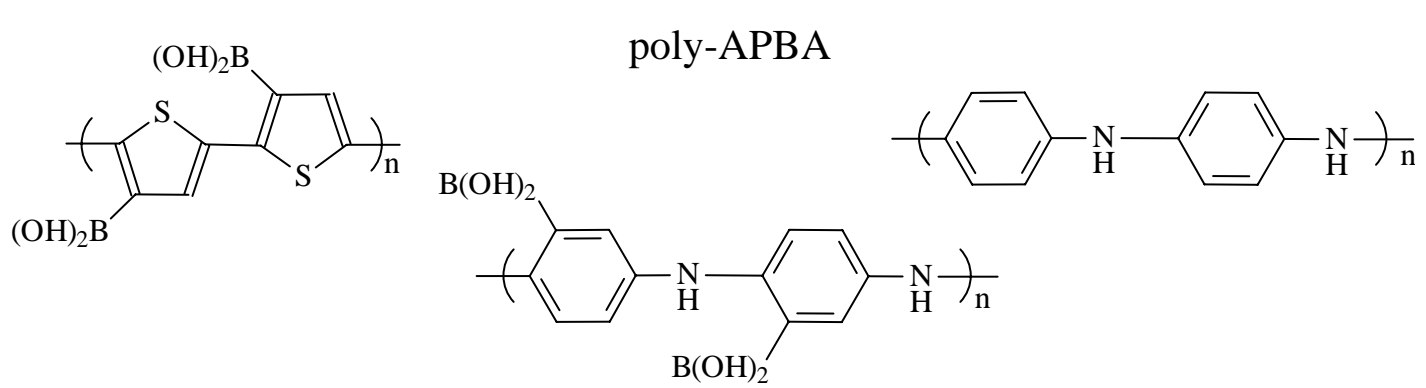

Figure 1. Piletsky et al. 
a)

b)

c)
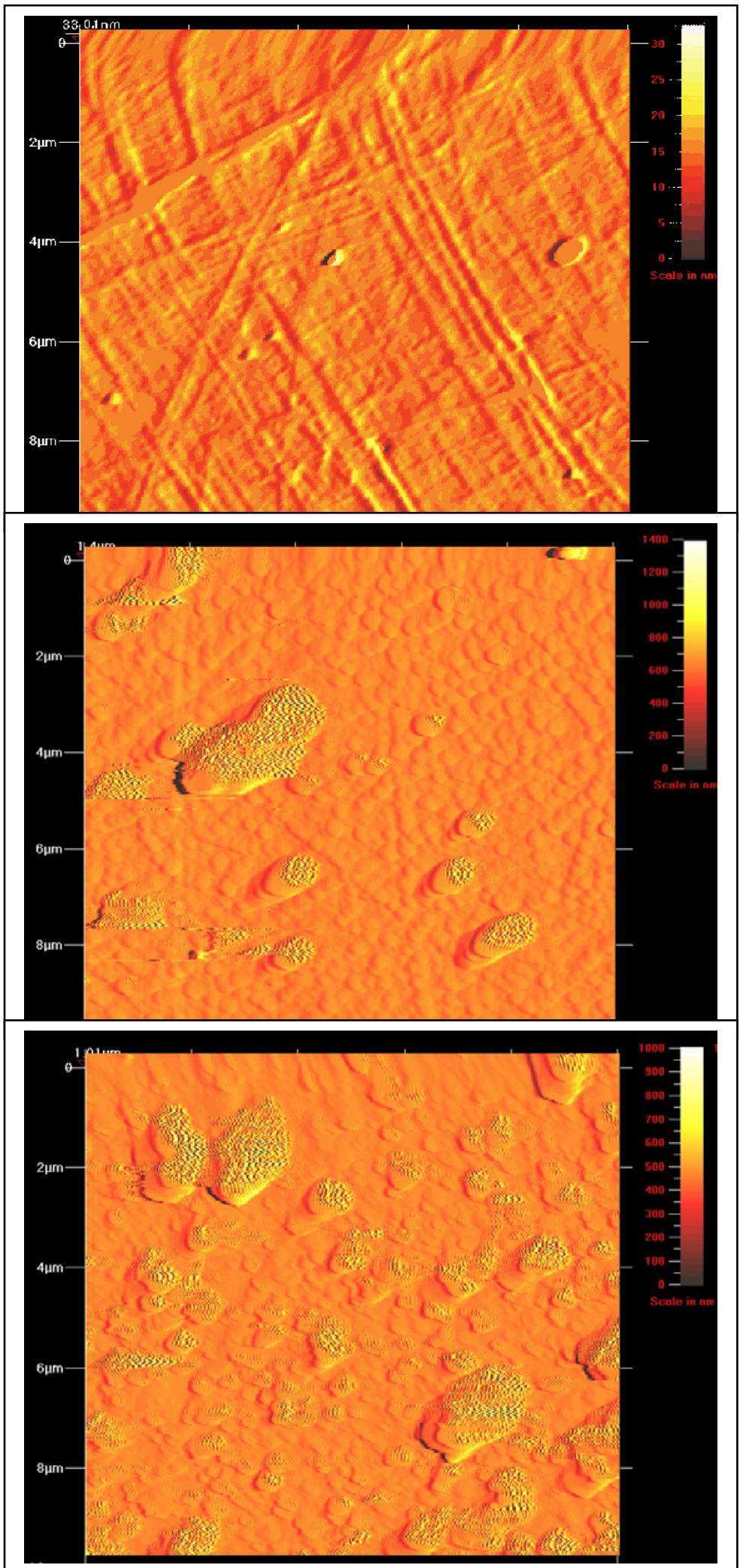

Figure 2. Piletsky et al. 


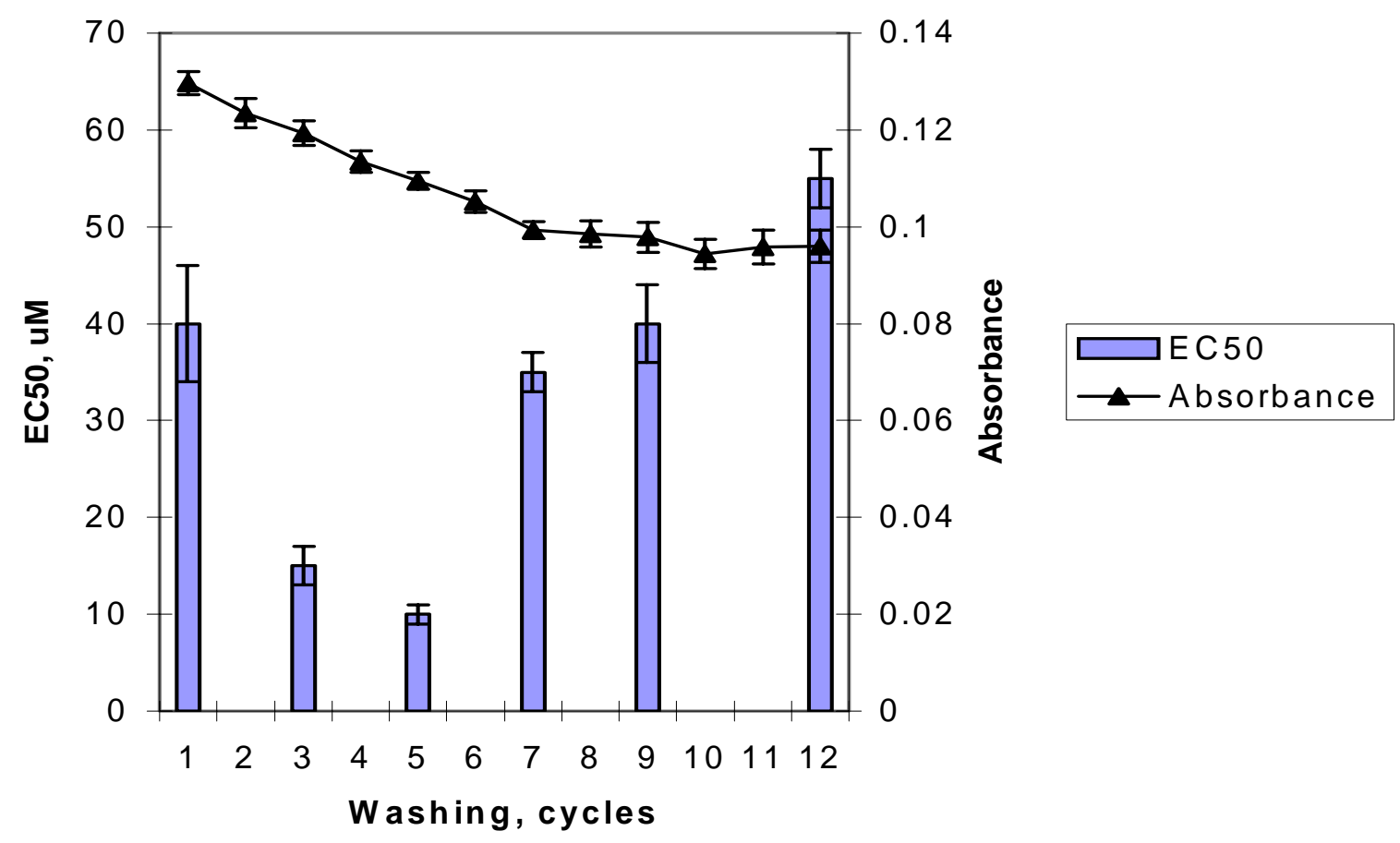

Figure 3. Piletsky et al. 
<smiles>CNCC(O)c1ccc(O)c(O)c1</smiles><smiles>NCC(O)c1ccc(O)c(O)c1</smiles><smiles>CC(C)NCC(O)c1ccc(O)c(O)c1</smiles><smiles>CNCC(O)c1cccc(O)c1</smiles><smiles>Oc1ccccc1O</smiles><smiles>CC(C)(C)NCC(O)c1cc(Cl)c(N)c(Cl)c1</smiles><smiles>CC(C)NCC(O)COc1cccc2[nH]ccc12</smiles>

Norepinephrine

Isoprotereno

Phenylephrin

Catechol

Clenbuterol

Pindolol

Propranolol
$46 \pm 4$

$300 \pm 15$

$\mathrm{K}_{\mathrm{D}}, \mu \mathrm{M}$

$9.2 \pm 2$

$21 \pm 2$

$>1000$

$>1000$

$464 \pm 33$

$157 \pm 4$

Figure 4. Piletsky et al. 


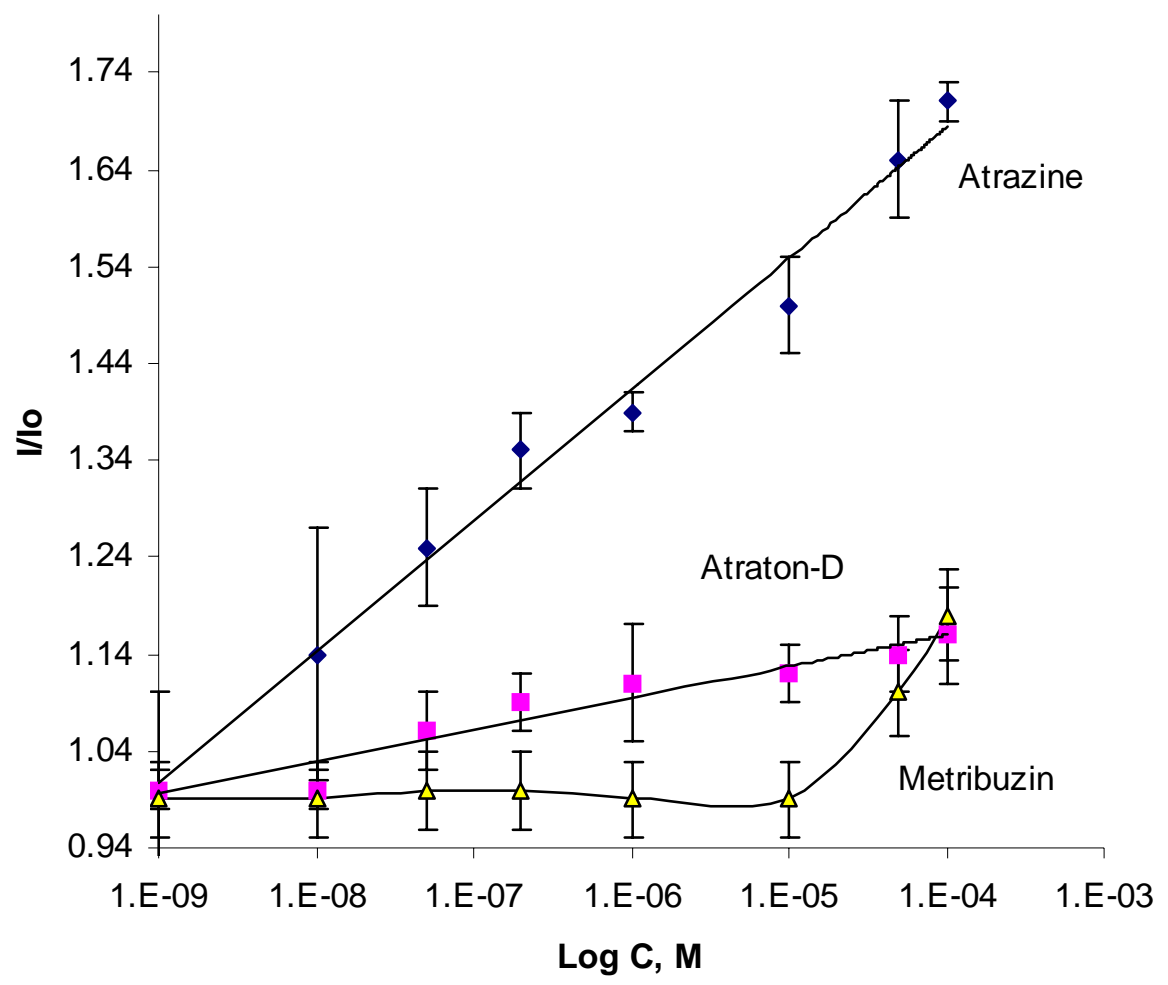

Figure 5. Piletsky et al. 